\title{
LABOR SUPPLY REACTION TO WAGE CUTS AND TAX INCREASES: A REAL-EFFORT EXPERIMENT
}

\author{
Tomoharu Mori \\ Hirofumi Kurokawa \\ Fumio Ohtake
}

September 2020

The Institute of Social and Economic Research

Osaka University

6-1 Mihogaoka, Ibaraki, Osaka 567-0047, Japan 


\title{
Labor supply reaction to wage cuts and tax increases: A real-effort experiment ${ }^{*}$
}

\author{
Tomoharu Mori ${ }^{\mathrm{a}}$, Hirofumi Kurokawa ${ }^{\mathrm{b}}$, and Fumio Ohtake
}

September 9, 2020

\begin{abstract}
We investigate the labor supply reaction to wage cuts and tax increases using a real-effort experiment. First, subjects perform a task and receive a reward with taxes deducted. Second, the wage cut treatment reduces the wage rate and the tax increase treatment increases the tax; wage and tax remain unchanged for the control group. The real wage is equal for both treatments, and both treatments had significantly smaller increases in effort levels than the control group. The effort level change did not differ between the treatments. Therefore, the net wage illusion and tax aversion identified in previous studies are absent.
\end{abstract}

Keywords: labor supply, net wage illusion, tax aversion

JEL codes: C91, H24, J24

\footnotetext{
* The authors are grateful for financial support from the Joint Usage/Research Center at ISER, Osaka University.

${ }^{a}$ Corresponding author: College of Comprehensive Psychology, Ritsumeikan University. E-mail: tmr15047@fc.ritsumei.ac.jp

b School of Economics and Management, University of Hyogo. kurokawa@em.u-hyogo.ac.jp

c Graduate School of Economics, Osaka University. ohtake@econ.osaka-u.ac.jp
} 


\section{Introduction}

The impacts of wage levels and changes on the labor supply and work motivation are important variables in labor and public economics (e.g., Chetty 2012; Gibbons 1998). Wages not only affect workers' well-being through consumption, but also directly affect their wellbeing through psychological and sociological processes (Akerlof 1982; Akerlof and Yellen 1990). Economic experiments have shown that wage levels can influence labor supply behaviors even when wages are not tied to workers' output or the effort levels are unobservable (e.g., Fehr et al. 1993, 1997). Some studies have also examined whether raising wages increases the labor supply (e.g., Gneezy and List 2016; Kube et al. 2012). Many studies discussed the fact that raising and lowering wages is an asymmetric process, and that the negative reaction to lowering wages has long been known as the downward rigidity of wages (e.g., Bewley 1999). The negative effects of lowering wages are also experimentally studied by Kube et al. (2013).

The taxation of workers is also an important topic in labor and public economics (e.g., Mirrlees 1971). Several experimental studies have investigated the effects of taxation on the labor supply, such as Swenson (1988) and Sillamaa (1999a, b). One basic but important question is whether workers react to taxations or the change in real wages. If workers react to real wages, other factors such as gross wages and the way taxes are collected should have no effect on the labor supply. If so, policymakers need only understand labor supply elasticity when setting taxes. However, recent experimental studies cited below have shown that workers determine their labor supply not only based on real wages, but also on gross wages and the reasons for wage changes.

There are two literature streams on the impact of taxes on effort levels. One shows that workers respond to pre-tax gross wages rather than post-tax real wages. Fochmann et al. (2013) called this phenomenon "net wage illusion" and experimentally tested workers by assigning them to one of three treatments with the same real wages but different gross wages and income tax rates $(0 \%, 25 \%$, and $50 \%)$ for performing a task (i.e., folding letters). Work performance 
was significantly higher for the treatments with higher gross wages (and higher income tax rates), indicating that workers determined their levels of effort according to their gross wages. Other studies show that individuals are strongly averse to having their money taken from them as taxes. Kessler and Norton (2016) called this phenomenon "tax aversion"; in their experiment, participants had their real wages reduced by $50 \%$ after 10 minutes of a typing task. One treatment described this reduction as "lowering wages" and the other as "introducing taxes." A comparison of the two treatments showed that performance increased for the wage reduction treatment (probably due to learning effects), while it did not increase for the tax introduction treatment.

These two results appear contradictory, in that the former shows that people respond less to taxes, while the latter shows a strong aversion to them. However, the results are not necessarily contradictory. On the one hand, the net wage illusion is a phenomenon related to inattention, under which people act without being aware of taxes. In Fochmann et al.'s (2013) experiment, taxes did not change within the session, which may indicate that less attention was paid to the tax. Tax aversion, on the other hand, refers to how people react to taxes when they are aware of them. Kessler and Norton's (2016) experiment introduced wage cuts and taxes within the session, which started from no tax and ranged to a high tax rate of $50 \%$, thus making it easier for participants to be aware of the mid-session changes.

We conducted a laboratory experiment to complement these studies and explain their results. The purpose of our study is twofold: first, to test whether the net wage illusion is observed when real wages vary within an experiment, and second, to test whether tax aversion is observed when tax rates change in an experiment. The experiment consisted of two rounds. In the first round, participants performed a slider task (Gill and Prowse 2012) for 10 minutes and received a reward (JPY 5 per slider). This reward was subject to a hypothetical income tax (JPY 1 per slider). That is, the real wage per subject is JPY 4 per slider. In the second round, the slider task was performed for 10 minutes in the same way, but the reward structure was different 
for three treatments: the first was the control group, which used the same setting as in the first round; the second was the wage cut treatment, in which the reward was lowered to JPY 3 per slider and the income tax (JPY 1 per slider) remained unchanged; and the third treatment was the tax increase treatment, under which the compensation remained at JPY 5 per slider, while the income tax was increased to JPY 3 per slider. The real wages under the wage cut and tax increase treatments were equal, but the explanation for the real wage reduction was different.

This experiment complements Fochmann et al.'s (2013) and Kessler and Norton's (2016) studies as follows. Wage cuts and tax increases are considered to be high in terms of attention because of the changes occurring within the session. Ours is a different setting from that of Fochmann et al. (2013), which does not change within the session, but is the same as that of Kessler and Norton (2016), which varies within the session. In our experiment, tax is imposed from the first round, while its level changes in the second round in the tax increase treatment. This setting is different from that of Kessler and Norton (2016), who introduced a new tax in the second round. In summary, our experiment was set up differently and we believe it can confirm the robustness of their results.

The main hypotheses of this study are as follows. If participants only determine their effort level in response to real wages, then the effort level should be lower under the wage cut treatment than for the control group. Similarly, the tax increase treatment should also have a lower effort level than the control group. Since real wages are equal, the effort levels for the wage cut and tax increase treatments will be equal. If participants only determine the effort level in response to gross wages (net wage illusion), the control group and tax increase treatment will show equal effort levels, as they have equal gross wages, while the wage cut treatment will have lower gross wages and, therefore, lower effort levels than the other two groups. If participants distinguish between wage cuts and tax increases and are more inclined to lower their effort levels in response to a tax increase (tax aversion), then the tax increase treatment will have a lower effort level than the wage cut treatment. 
The results show that the increase in the effort level from the first to the second round was significantly smaller under the wage cut and tax increase treatments than for the control group, lowered by the decline in real wages. There was no significant difference between the wage cut and tax increase treatments. The difference between the control group and wage cut treatment implies no net wage illusion. Further, the absence of a difference between the wage cut and tax increase treatments implies no tax aversion either. The results of this study are different from those of Fochmann et al. (2013) and Kessler and Norton (2016), thus making a novel contribution to the literature.

The results of the current study show the "classic" result that individuals change their effort level in response to a change in real wages. The reason for the lack of a net wage illusion may be that participants were more likely to see changes in real wages due to wage cuts and tax increases during the session. The reason for the lack of tax aversion may be that taxes were introduced from the first round and participants were thus not averse to their increase.

Our study contributes to the literature on behavioral biases on taxes, for example, tax salience (e.g., Chetty et al. 2009; Feldman and Ruffle 2015), non-equivalence between income and consumption taxes (Blumkin et al. 2012; Kurokawa et al. 2016), and overestimation of the changes in tax rates compared to changes in tax bases (Blaufus et al. 2013). Our study also contributes to the experimental literature on tax evasion and compliance (e.g., Doerrenberg and Duncan 2014; Pántya et al. 2016).

The remainder of this paper is organized as follows. Section 2 describes the experimental design, Section 3 explains the hypotheses of the study, Section 4 presents the results, and Section 5 discusses the results and draws conclusions.

\section{Experimental Design}

The experiment was conducted at the Economic Laboratory of the Institute of Social and Economic Research, Osaka University, from June to October 2017, with 150 students 
participating in six sessions. The subjects were university students who were enrolled in the institute's subject pool. Participants received a JPY 1,200 reward for participation, with additional rewards depending on the results of the real-effort task described below. The average amount of total compensation (including participation fee) was JPY 1,883 (around USD 17 at the time). The experiment was programmed by zTree (Fischbacher 2007). The task instructions are described in the Appendix.

A slider task (Gill and Prowse 2012) was used as the real-effort task to be performed by the subjects. The slider task involves moving sliders on a computer screen to target positions using only the mouse, as shown in Figure 1. At the beginning, all sliders show 0 and are at the left end of the axis. When moved to the right end of the axis, they show 100. If subjects can move the slider to position 50, they get one point. The sliders can be moved as many times as needed. Forty-eight sliders were displayed on a single screen. Pressing the "Next" button in the upperright corner of the screen displayed a new screen. ${ }^{1}$ There were five screens with sliders. Therefore, subjects could earn a maximum of 240 points. In line real-world decision making, the design allowed subjects to choose "leisure," that is, not performing the task. As in Kessler and Norton (2016), Internet use was allowed as leisure. However, few subjects used the Internet.

\footnotetext{
${ }^{1}$ On the second and subsequent screens, the "Previous" button was shown in the upper-left corner, and when pressed, the previous screen was displayed.
} 


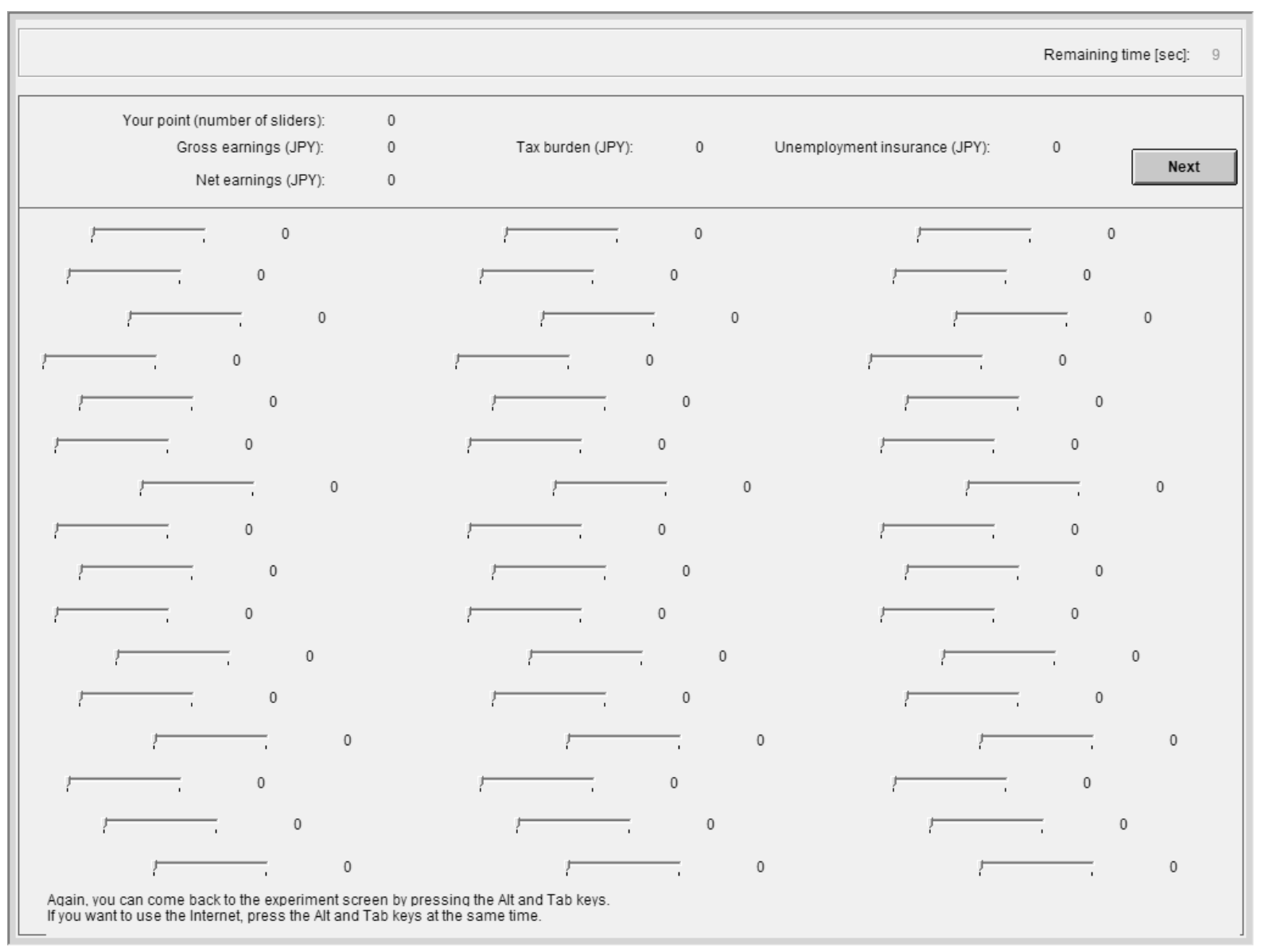

Figure 1. Slider task

Our experimental design is based on that of Kessler and Norton (2016), but our experimental purpose is an examination of the effect of lower real wages due to a tax increase for labor supply. Therefore, while Kessler and Norton (2016) only introduced taxes in the second round for a specific treatment, we introduced them in the first round for all treatments.

The subjects performed two rounds of this task. The time limit for each round was 10 minutes. At the beginning of the experiment, subjects were told that they would perform two rounds, and the content of the first round was explained. That of the second round was explained after the first round.

In the first round, we set a gross wage of JPY 5 per point for all treatments. Further, gross wages were taxed at JPY 1 per point, which means real wages were set at JPY 4 per point. Subjects were informed that the tax would be returned to the experimenters and used for future 
experiments. The results of the first round were used in the analysis, as they were considered to show the subjects' ability. The screen showed gross wages, taxes, and nominal wages at the top, according to the results of the work in progress.

In the second round, subjects' gross wage, tax rate, and/or net wage were changed. The change depended on the experimental treatment. In the control group ( 2 sessions, $N=52)$, the experiment was conducted using the same conditions as in the first round. In other words, the gross wage was JPY 5 per point with a tax of JPY 1 per point, resulting in a net wage of JPY 4 per point. Under the wage cut treatment ( 2 sessions, $N=46$ ), the gross wage was lowered to JPY 3 per point. Taxes were still set at JPY 1 per point, the same as in the first round. Therefore, the net wage was set to JPY 2 per point. Under the tax increase treatment ( 2 sessions, $N=52$ ), the nominal wage remained at JPY 5 per point, but the tax amount was increased to JPY 3 per point. Therefore, the net wage was JPY 2 per point (equal to the wage cut treatment).

\section{Hypotheses}

The experimental parameters are summarized in Table 1. In the first round, the conditions were the same under all treatments (the net wage was JPY 4 per point), and the effort level should have been equal if the subjects were randomly assigned. In the second round, the gross and net wages varied between treatments, meaning that the effort level could have been different. 
Table 1. Experimental parameters

\begin{tabular}{|c|c|c|c|c|c|}
\hline & & $\begin{array}{l}\text { Control } \\
(\mathrm{N}=52)\end{array}$ & $\begin{array}{l}\text { Wage cut } \\
(\mathrm{N}=46)\end{array}$ & & $\begin{array}{c}\text { Tax increase } \\
(\mathrm{N}=52)\end{array}$ \\
\hline \multicolumn{6}{|c|}{ First round } \\
\hline & Gross wage & 5 & & 5 & 5 \\
\hline & Tax burden & 1 & & 1 & 1 \\
\hline & Net wage & 4 & & 4 & 4 \\
\hline \multicolumn{6}{|c|}{ Second round } \\
\hline & Gross wage & 5 & & 3 & 5 \\
\hline & Tax burden & 1 & & 1 & 3 \\
\hline & Net wage & 4 & & 2 & 2 \\
\hline
\end{tabular}

Note: The numbers represent the rewards per experimental point in JPY.

The control group has the same conditions as in the first and second rounds, the net wage being JPY 4 per point. The wage cut and tax increase treatments had net wages of JPY 2 per point in the second round. From the traditional economics perspective, the net wage affects the effort level of the subject, not the gross wage. Therefore, the effort level in the second round was expected to be higher for the control group than for the wage cut or tax increase treatments. Additionally, the effort levels were expected to be equal for the wage cut and tax increase treatments. Therefore, we posit a hypothesis based on traditional economics for the second round's effort level:

Hypothesis 1 (traditional economics): Control $>$ Wage cut treatment $=$ Tax increase treatment.

As shown by Fochmann et al.'s (2013) experiment, subjects may change their motivation depending on nominal wages, as well as real wages. In our experiment, the wage cut and tax increase treatments had the same net wages but different gross wages. The gross wage for the wage cut treatment was JPY 5 per point, which was equal to that of the control group, while 
the gross wage for the tax increase treatment was JPY 3 per point. If subjects focused only on gross and not real wages, we would expect the effort level in the second round to be higher under the tax increase treatment than under the wage cut one, although the net wage is the same (net wage illusion). The control group and tax increase treatment would be expected to have the same gross wage. Therefore, we propose a hypothesis based on net wage illusion for the second round's effort level:

Hypothesis 2 (net wage illusion): Control $=$ Tax increase treatment $>$ Wage cut treatment

The reasons for the decline in net wage under the wage cut and tax increase treatments are different. For the wage cut treatment, the reason is the reduction in wages. By contrast, for the tax increase treatment, the reason is the increase in the tax burden. According to Kessler and Norton (2016), even when the net wage remains the same, tax increases reduce work motivation more than wage cuts (tax aversion). ${ }^{2}$ Combined with the lower effort level for the wage cut treatment than for the control group in both Hypotheses 1 and 2, we posit a hypothesis based on tax aversion for the second round's effort level:

Hypothesis 3 (tax aversion): Control $>$ Wage cut treatment $>$ Tax increase treatment

\section{Results}

Figure 2 shows the effort level, measured by the number of correctly moved sliders in each treatment and round. In the first round, the mean effort level is $92.7,96.2$, and 97.7 for the control group, wage cut treatment, and tax increase treatment, respectively. The difference

\footnotetext{
${ }^{2}$ While the tax rate in the first round is $20 \%$, those in the second round are $20 \%, 33.3 \%$, and $60 \%$ for the control group, wage cut treatment, and tax increase treatment, respectively.
} 
between the control group and wage cut treatment is not significant (t-test: $t=-0.99, p=0.33){ }^{3}$

The difference between the control group and tax increase treatment is also not significant $(\mathrm{t}-$ test: $t=-1.23, p=0.22) .{ }^{4}$ There is no difference in the effort level for the same conditions, which confirms successful random assignment of subjects.

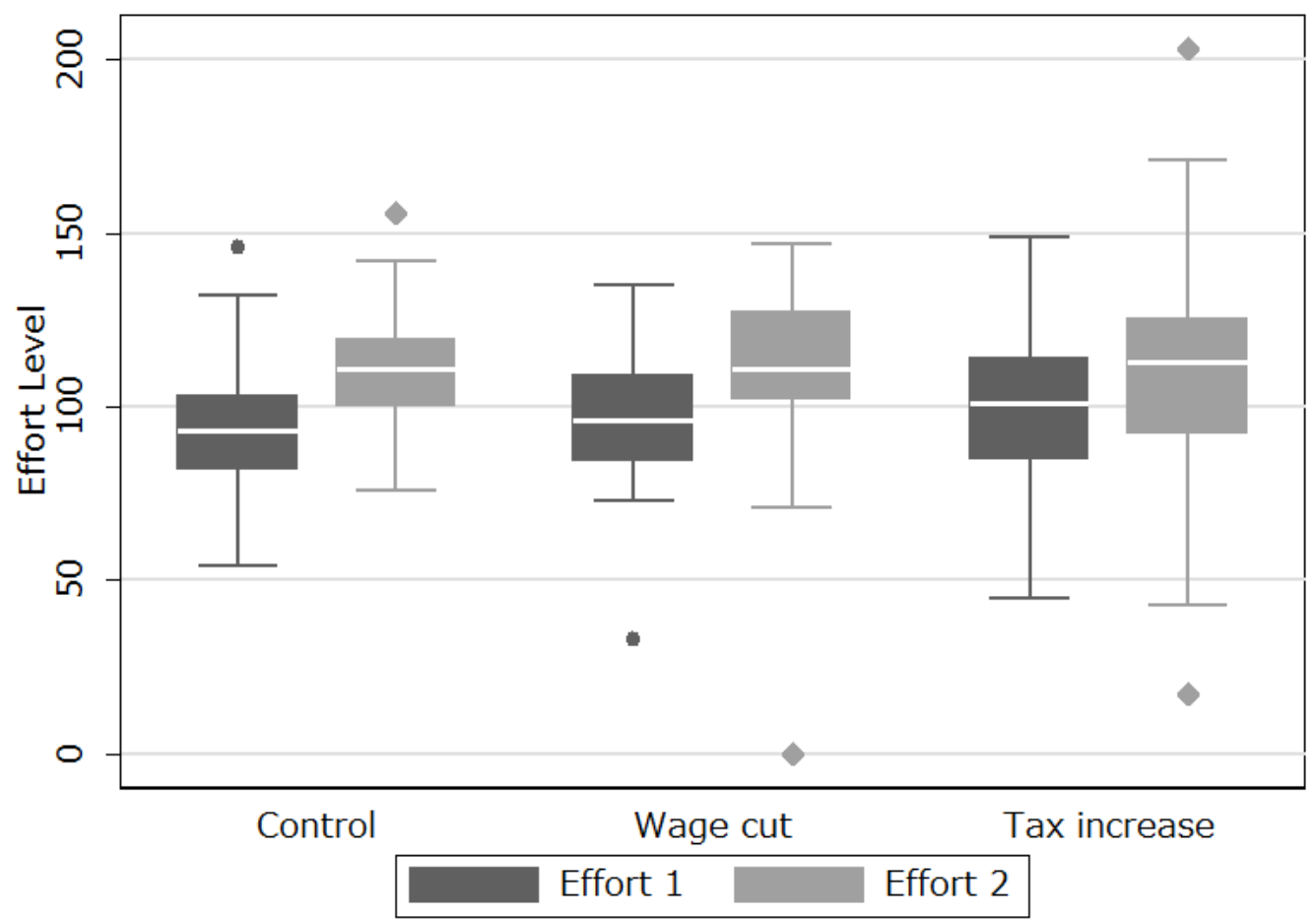

Note: "Effort 1" represents the effort level in the first round and "Effort 2" the effort level in the second round.

Figure 2. Effort levels in each treatment and round

The mean effort levels in the second round are 111.1, 109.5, and 109.7 for the control group, wage cut treatment, and tax increase treatment, respectively. All groups have higher effort levels than in the first round. The difference between the control group and wage cut treatment is not significant (t-test: $t=0.39, p=0.70$ ). There is also no significant difference between the

\footnotetext{
${ }^{3}$ We hereafter report the $p$-value of the two-sided t-test. We employ conservative methods, although some hypothesis tests are suitable for the one-sided t-test.

${ }_{4}$ The difference between the wage cut and tax increase treatments is also not significant ( $\mathrm{t}$-test: $t=-0.34, p$ $=0.73)$.
} 
control group and tax increase treatment ( $\mathrm{t}$-test: $t=0.29, p=0.77)$. The net wage is higher for the control group than for the wage cut or tax increase treatments, but there is no difference in the effort level between the control group and wage cut or tax increase treatments. The two treatments have different reasons for lower net wage, but there is no significant difference between them in the effort level for the second round (t-test: $t=0.04, p=0.97$ ).

Result 1 (effort level in the second round): Control = Wage cut treatment $=$ Tax increase treatment

When looking at the effort level in the second round, there is no difference between treatments. However, there is a difference in the change in effort levels from the first and second rounds. The lower real wages under the wage cut and tax increase treatments may have motivated subjects less than in the control group. Figure 3 shows the differences in the effort levels between the first and second rounds by treatment. The control group increased its effort level by 18.4 points, while the wage cut and tax increase treatments increased their effort levels by only 13.3 points and 12.1 points, respectively. 


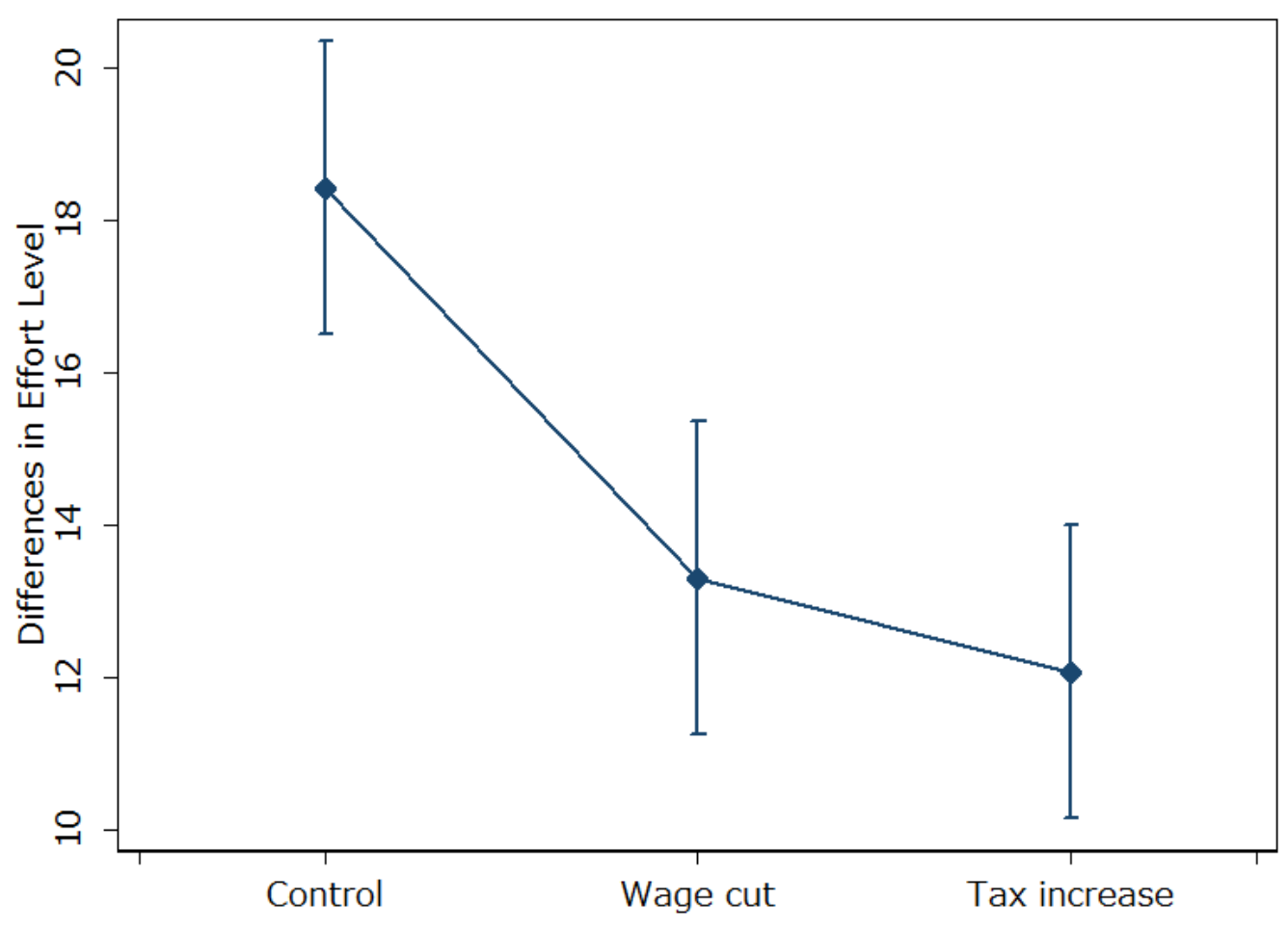

Note: The error bars represent standard errors.

Figure 3. Changes in effort level

The difference between the control group and wage cut treatment is significant regarding the changes in the effort level (t-test: $t=1.90, p=0.06$ ). The difference between the control group and tax increase treatment is also significant ( $\mathrm{t}$-test: $t=2.42, p=0.02)$. These results indicate that the decline in real wages resulted in a lower growth of the effort level. By contrast, the difference between the wage cut and tax increase treatments is not significant ( $\mathrm{t}$-test: $t=0.04$, $p=0.34)$. The differences in the reasons for real wage declines are shown to have no effect on effort increases.

Result 2 (differences in effort level between first and second round): Control $>$ Wage cut treatment $=$ Tax increase treatment

Based on these results, Hypothesis 1, which posits that subjects' labor supply depends only 
on real wages, is supported. However, there is no support for the net wage illusion (Hypothesis 2), in which the effort level is determined by gross wages, or for tax aversion (Hypothesis 3), in which the reduction in real wages due to higher taxes is averted.

Table 2 shows the results of the ordinary least squares regression analysis controlling for the characteristics of subjects. As treatment dummies, we control the wage cut and tax increase treatment dummies, while the control group serves as the baseline. We also control for slider task experience, gender (female), and graduate students using dummies. We present the coefficients and p-values for each variable and the F-value of whether the value of the dependent variable is the same between the wage cut and tax increase treatments. 
Table 2. Regression analysis

\begin{tabular}{lccc}
\hline \multicolumn{1}{c}{ Dependent variable } & Effort 1 & Effort 2 & Differences \\
& $(1)$ & $(2)$ & $(3)$ \\
\hline Wage cut & 2.179 & -2.653 & $-4.998^{*}$ \\
Tax increase & $(3.352)$ & $(4.237)$ & $(2.718)$ \\
& 2.620 & -3.087 & $-5.907 * *$ \\
Experience with slider & $(3.719)$ & $(4.535)$ & $(2.575)$ \\
tasks & $10.450^{* * *}$ & 4.769 & $-6.479 * * *$ \\
& $(3.264)$ & $(4.463)$ & $(2.479)$ \\
Female & $-5.642^{*}$ & -3.351 & 2.721 \\
& $(3.053)$ & $(3.606)$ & $(2.423)$ \\
Graduate student & $10.679 * * *$ & $11.314 * *$ & -0.179 \\
Effort 1 & $(3.364)$ & $(4.646)$ & $(2.622)$ \\
& & & 0.076 \\
Constant & & & $(0.092)$ \\
& $89.162^{* * *}$ & $108.163^{* * *}$ & 12.200 \\
\hline Wage cut $=$ Tax increase & $\mathrm{F}(1,144)=0.01$ & $\mathrm{~F}(1,144)=0.01$ & $\mathrm{~F}(1,143)=0.10$ \\
\hline Observations & 150 & 150 & 150 \\
$\mathrm{R}^{2}$ & 0.186 & 0.069 & 0.093 \\
\hline
\end{tabular}

Note: "Effort 1" represents the effort level in the first round and "Effort 2" the effort level in the second round. "Differences" represents the difference between Effort 2 and Effort 1. Robust standard errors are clustered by subject. *, **, and *** represent significance at the $10 \%, 5 \%$, and $1 \%$ levels, respectively.

The dependent variable in the first column is the effort level in the first round. As per Figure 1, there is no difference in the effort level between the control group and wage cut or tax increase treatments. There is also no difference in the effort level between the wage cut and tax increase treatments. Those who had experience with a slider task had an effort level higher by 10.7 points than those who have not. The experience also caused the adaptation of the task. The effort level is slightly lower for females and higher for graduate students (which may reflect 
their computer skills).

The dependent variable in the second column is the effort level in the second round. The effort level for the wage cut and tax increase treatments is lower than for the control group, but not significantly different. There is also no significant difference in the effort level between the wage cut and tax increase treatments. Regarding the effort level in the second round, there is no difference between the effort levels of those who have had experience with a slider task in the past and the others. The effect of learning the task disappears in the second round. Graduate students have higher effort levels and there is no significant gender difference.

The dependent variable in the third column is the difference in the effort level between the first and second rounds. In this analysis, we control for the effort level in the first round. Compared to the control group, the increase in the effort level is significantly smaller for the wage cut treatment, by 5.0 points. The increase is significantly smaller under the tax increase treatment, by 5.9 points. However, there is no significant difference in the increase in the effort level between the wage cut and tax increase treatments. The increase in the effort level is smaller for those with slider task experience, indicating a convex learning curve. Both the female and graduate student dummies are not significant.

These results are robust when controlling for these new variables. In other words, Hypothesis 1 is still supported, and there is no evidence of the net wage illusion or tax aversion.

\section{Discussion and Conclusions}

This study examines whether a drop in net wages differently impacts on labor supply according to whether wages are cut or taxes increased. Recent studies show that, when the gross wage is different but the net wage is the same due to taxes, a higher gross wage leads to a higher labor supply, which is called the net wage illusion (Fochmann et al. 2013). Studies also show that, even if the net wage is the same, tax introduction has a greater impact on reducing the labor supply than lowering wages, which is called tax aversion (Kessler and 
Norton 2016). We conducted complementary laboratory experiments to test these opposite behavioral economics hypotheses.

In our experiment, there was no difference in the level of the labor supply when wages were cut or taxes were increased compared to the control group, for which real wages remained unchanged. Compared to the control group, the increase in labor supply was smaller when wages were cut or taxes increased. There was no difference between the impacts of a wage cut or a tax increase on the extent of the increase in the labor supply. Therefore, neither the net wage illusion nor tax aversion were observed in our experiment.

The lack of differences between treatments regarding the effort level may be due to the fact that a slider task does not respond to incentives for between-subject comparisons. Araujo et al. (2016) showed that, even if there is a $1500 \%$ difference in incentives, productivity differs only by $5 \%$. In our experiment, the difference in incentives was $50 \%$, so we did not observe an impact on productivity. However, the analysis of the difference in the effort level between the first and second rounds captured within-subject changes and allowed for a comparison between subjects. Specifically, the increase in the effort level was around $30 \%$ lower when the incentive was reduced by $50 \%$. Our results suggest that the slider task is less responsive to incentives between subjects, but more responsive to changes in incentives within subjects.

One possible reason for the absence of the net wage illusion is that participants were more likely to notice the changes in real wages due to wage cuts and tax increases during the session. By contrast, Fochmann et al. (2013) employed a between-subject design, which may have prevented subjects from being strongly aware of the levels of nominal and real wages.

The absence of tax aversion may have been due to the fact that tax was introduced from the first round, so the impact of the tax increase in the second round was assessed as small. Kessler and Norton (2016) introduced the tax only in the second round, meaning that the combined effect of the wage reduction from the tax increase and the "surprise effect" of the tax introduction was observed. In our study, only the effect of the wage reduction caused by the 
tax increase was observed. These results suggest that raising an existing tax has a similar impact on the labor supply as lowering wages, whereas introducing a new tax has a stronger impact on the labor supply than lowering wages.

This implication might be extended to the general institutional design. That is, introducing a new system, rather than changing parameters within an existing one, could generate a greater response. The changes in incentives caused by institutional changes will only take effect if individuals are aware of them. Studying how people perceive institutional change could thus have significant implications for institutional design.

There are some limitations to our experiment. First, under the wage cut treatment, the amount of compensation changed without changing the amount of tax, so the tax rate had increased. This might be why we did not see a difference between the wage cut and tax increase treatments. To avoid this problem, we can use an experimental design that compares wage cut to tax increase, while keeping the tax rate constant. Second, our study did not make a direct comparison between tax introduction and its increase. To show the two are different, we could use an experimental design that allows for the direct comparison between them. Since the experimental results may vary depending on the experimental settings, it is necessary to consider various experimental conditions when conducting experiments.

\section{References}

Akerlof, G. A. (1982). Labor contracts as partial gift exchange. Quarterly Journal of Economics, 97(4), 543-569.

Akerlof, G. A., and Yellen, J. L. (1990). The fair wage-effort hypothesis and unemployment. Quarterly Journal of Economics, 105(2), 255-283.

Araujo, F. A., Carbone, E., Conell-Price, L. et al. (2016). The slider task: An example of restricted inference on incentive effects. Journal of the Economic Science Association, 2(1), $1-12$. 
Blaufus, K., J. Bob, J. Hundsdoerfer, D. Kiesewetter, and J. Weimann. (2013). Decision heuristics and tax perception-An analysis of a tax-cut-cum-base-broadening policy. Journal of Economic Psychology, 35, 1-16.

Blumkin, T., B. J. Ruffle, and Y. Ganun. (2012). Are income and consumption taxes ever really equivalent? Evidence from a real-effort experiment with real goods. European Economic Review 56(6), 1200-1219.

Chetty, R. (2012). Bounds on Elasticities with Optimization Frictions: A Synthesis of Micro and Macro Evidence on Labor Supply. Econometrica, 80(3), 969-1018.

Chetty, R., A. Looney, and K. Kroft, (2009). Salience and taxation: theory and evidence. American Economic Review, 99(4), 1145-77.

Doerrenberg, P., and Duncan, D. (2014). Experimental evidence on the relationship between tax evasion opportunities and labor supply. European Economic Review, 68, 48-70.

Fehr, E., Gächter, S., and Kirchsteiger, G. (1997). Reciprocity as a contract enforcement device: experimental evidence. Econometrica, 65(4), 833-860.

Fehr, E., Kirchsteiger, G., and Riedl, A. (1993). Does fairness prevent market clearing? An experimental investigation. Quarterly Journal of Economics, 108(2), 437-459.

Fehr, E., and Tyran, J. R. (2001). Does money illusion matter? American Economic Review, 91(5), 1239-1262.

Feldman, N. E., and B. J. Ruffle. (2015). The Impact of including, adding, and subtracting a tax on demand. American Economic Journal: Economic Policy, 7(1), 95-118 Fischbacher, U. (2007). z-Tree: Zurich toolbox for ready-made economic experiments. Experimental Economics, 10(2), 171-178.

Fochmann, M., Weimann, J., Blaufus, K., Hundsdoerfer, J., and Kiesewetter, D. (2013). Net wage illusion in a real-effort experiment. The Scandinavian Journal of Economics, 115(2), 476-484. 
Gibbons, R. (1998). Incentives in Organizations. Journal of Economic Perspectives, 12(4), $115-132$.

Gill, D., and Prowse, V. (2012). A structural analysis of disappointment aversion in a real effort competition. American Economic Review, 102(1), 469-503.

Kessler, J. B., and Norton, M. I. (2016). Tax aversion in labor supply. Journal of Economic Behavior and Organization, 124, 15-28.

Kube, S., Maréchal, M. A., and Puppe, C. (2012). The currency of reciprocity: gift exchange in the workplace. American Economic Review, 102(4), 1644-1662.

Kube, S., Maréchal, M. A., and Puppe, C. (2013). Do wage cuts damage work morale? Evidence from a natural field experiment. Journal of the European Economic Association, 11(4), 853-870.

Kurokawa, H., Mori, T, and Ohtake, F. (2016). A choice experiment on taxes: are income and consumption taxes equivalent? ISER Discussion Paper, 966.

Mirrlees, J. A. (1971). An exploration in the theory of optimum income taxation. The Review of Economic Studies, 38, 175-208.

Pántya, J., Kovács, J., Kogler, C., and Kirchler, E. (2016). Work performance and tax compliance in flat and progressive tax systems. Journal of Economic Psychology, 56, 262273.

Shafir, E., Peter, D., and Tversky, A. (1997). Money illusion. The Quarterly Journal of Economics, 112(2), 341-374.

Sillamaa, M.-A. (1999a). How work effort responds to wage taxation: A non-linear versus a linear tax experiment, Journal of Economic Behavior and Organization 39, 219-233.

Sillamaa, M.-A. (1999b), How work effort responds to wage taxation: An experimental test of a zero top marginal tax rate, Journal of Public Economics, 73, 125-134.

Swenson, C. W. (1988). Taxpayer behavior in response to taxation: an experimental analysis, Journal of Accounting and Public Policy 7, 1-28. 
Instruction translated to English

\section{Instruction for the first round (common to all treatment)}

As a reward for participating in this experiment, you will receive 1,200 yen. In addition, the experiment allows you to do certain tasks. The total duration of the task is 20 minutes (10 minutes $\mathrm{x} 2$ times). The reward for the experiment will be determined based on the performance of the task. You will do the task for 10 minutes after this explanation, and then do the task for another 10 minutes after the additional explanation. Please fill out a questionnaire after the tasks.

The task you will be doing this time is the "Slider Task". For this task, 48 sliders will appear on your computer screen, as shown in the figure on the next page ${ }^{5}$, so adjust as many sliders as possible to show a number of 50 .

Initially each slider shows a number of 0 , and each slider can be moved up to a maximum of a number of 100 . The number of each slider is displayed to the right of the slider. Use the mouse to move each slider as you like (do not use the keyboard). You can readjust the position of the slider as many times as you like. There are five slider screens in all. Press "Next" at the top right to move to the next screen. Move to the previous screen by "Previous". It doesn't matter which slider on any screen you move.

Your point in this task will be the number of sliders that show 50 at the end of 10 minutes.

You will do the task twice in total. The reward for the first round will be explained in the next

\footnotetext{
5 This figure is same as Figure 1.
} 
paragraph, and the reward for the second round will be explained before you start the second round.

For the first task, there will be no "unemployment" for not being able to perform the task ${ }^{6}$. the reward for the first task is [ 5 yen per point]. However, there will be a tax on the reward for this experiment. The tax is [ 1 yen per point]. This tax will be returned to the experimenter to be used for future experiments. No unemployment insurance premiums (unemployment insurance premiums are those returned to the experimenter to be used for unemployment benefits for experiment participants who become unemployed in future experiments) will be paid for this experiment. After the experiment, you will be paid after taxes and unemployment insurance premiums are deducted.

During the 10-minute task, you are allowed to stop working and take a break. You can also use the Internet. To turn the screen into a web browser, press the "Alt" key and the "Tab" key. You can return to the original screen by pressing "Alt" key and "Tab" again. If you have any questions, please raise your hand and call a staff member.

\section{Instruction for the second round}

The second round, as the first round, you will do the slider task for 10 minutes, during which time you may stop and take a break. You can also use the Internet. To turn the screen into a web browser, press the "Alt" key and the "Tab" key. You can return to the original screen by pressing the "Alt" key and "Tab" again. If you have any questions, please raise your hand and call a staff member.

\footnotetext{
${ }^{6}$ This "unemployment" is not occurred in all treatments and rounds reported in this paper. As part of a larger project, we also varied the existence of unemployment and unemployment insurance. We find smaller effects of them probably due to the fact that the settings are too complex for the subjects to understand.
} 
There will be no "unemployment" for not being able to do the task on the second task, and the reward for the second task will be [5 yen per point] (replace this amount to [3 yen per point] in Wage cut treatment). However, there will be a tax on the reward for this experiment. The tax is [1 yen per point] (replace this amount to [3 yen per point] in Tax increase treatment). This tax will be returned to the experimenter to be used for future experiments. No unemployment insurance premiums (unemployment insurance premiums are those returned to the experimenter to be used for unemployment benefits for experiment participants who become unemployed in future experiments) will be paid for this experiment. After the experiment, you will be paid after taxes and unemployment insurance premiums are deducted. 